\title{
Patterns of Calcium- and Chloride-lon Disorders and Predictors among Obese Outpatient Adults in Southern Ethiopia
}

This article was published in the following Dove Press journal: Diabetes, Metabolic Syndrome and Obesity: Targets and Therapy

\author{
Abebe Timerga' \\ Kassahun Haile $\mathbb{D}^{2}$ \\ 'Department of Biomedical Science, \\ College of Medicine and Health Sciences, \\ Wolkite University, Wolkite, Ethiopia; \\ ${ }^{2}$ Department of Medical Laboratory \\ Science, College of Medicine and Health \\ Sciences, Wolkite University, Wolkite, \\ Ethiopia
}

Background: Obesity is a condition characterized by abnormal or excess accumulation of fat in body tissue, which may impair health and result in electrolyte derangement. Hypercalcemia and hypochloremia are significant problems in obese patients, and can cause substantial morbidity and mortality. Determination of patterns of calcium and chloride may play a major role in the management of obese patients. Therefore, this study aimed to determine calcium and chloride disorders and their predictors among obese adults in the outpatient department at Wolkite University Specialized Hospital, southern Ethiopia from May to August 2020.

Methods: This institution-based cross-sectional study was conducted on 250 obese adults attending the outpatient department from May to August 2020. Structured questionnaires through face-to-face interviews and participants' medical records were used to collect information on determinants related to calcium- and chloride-ion disturbances. Levels of serum calcium and chloride were measured using an ion-selective electrode analyzer. Bivariate and multivariate logistic regression analyses were done to identify determinants associated with calcium and chloride disorders. Using ORs and 95\% CIs, $P<0.05$ was considered significant.

Results: Among the 250 patients, $18 \%$ (95\% CI 53.02-111) and 17.6\% (95\% CI 0.78-12) of study participants were hypochloremic and hypercalcemic, respectively. Age $\geq 50$ years (AOR 3.58, 95\% CI 2.57-11.10), diuretic use (AOR 2.35, 95\% CI 1.31-4.23), and obesity (AOR, 6.82, 95\% CI 2.26-14.62) were independent predictors of hypochloremia on multivariate logistic regression, and obesity (AOR 9.21, 95\% CI 2.50-14.81), overweight (AOR 8.32, 95\% CI 1.61-10.20) and physical inactivity (AOR 4.28, 95\% CI 1.71-10.44) were predictors of hypercalcemia.

Conclusion: High burdens of hypochloremia (18\%) and hypercalcemia (17.6\%) were observed in these patients. Increased age, diuretic use, being overweight, and physical inactivity were predictors of electrolyte disorders. The findings of this study should be taken into consideration to implement preventive interventions on these predictors in obese patients. Promoting sufficient fruit and vegetable consumption and physical exercise and determination of serum-chloride and -calcium levels in adult overweight/obese patients are recommended to minimize the emergence of electrolyte disorders.

Keywords: obesity, hypochloremia, hypercalcemia, southern Ethiopia

\section{Introduction}

Obesity is a condition characterized by abnormal or excess accumulation of fat in body tissue to the extent that health may be impaired as a result of positive energy balance and weight gain. ${ }^{1,2}$ Globally, around 1.5 billion people are obese, and
Correspondence: Abebe Timerga Department of Biomedical Science, College of Medicine and Health Sciences, Ethiopia

Tel +25I $92059-2604$

Fax +25I II 322004 I

Email abebetimerga I25@gmail.com
Diabetes, Metabolic Syndrome and Obesity: Targets and Therapy 2021:14 1349-1358 
a study conducted in sub-Saharan African countries showed that $15.9 \%$ of the population were overweight. ${ }^{3}$ An Ethiopian study indicated $12.1 \%$ and $2.8 \%$ burdens of overweight and obesity in urban settings, respectively. Another study conducted in Addis Ababa revealed that $25.7 \%$ of women were overweight and $10.2 \%$ obese. Obese patients differ in both amount of excess fat and regional distribution throughout the body. ${ }^{4}$

Obesity encompasses clinical and laboratory test derangement linked to increased risk of cardiovascular diseases, type 2 diabetes mellitus (T2DM), and derangement of electrolytes and malignancies with unfavorable outcomes. Body-mass index (BMI) and waist circumference (WC) are important variables in estimating and measuring obesity. ${ }^{3,5}$

BMI provides the most useful crude population-level measure of risk and complications associated with obesity. However, it does not provide a measure of body fat distribution and may not correspond to the same degree of fatness or related health risks among different patients and populations, unlike WC. ${ }^{6}$

Therefore, measuring WC gives simple, evident and practical way of identifying obesity-related health complications due to intra-abdominal fat distribution, ${ }^{3,7}$ and appropriately reveals excess fat in intra-abdominal depots, which has a high risk of adverse health outcomes.

Electrolytes are charged molecules that are important in maintaining signal transduction, acid-base balance, blood clotting, body fluid, and muscle contractions. A number of common electrolytes, eg, potassium, sodium, magnesium, calcium, and chloride, are found in the body, each with specific and valuable functions, but most are specifically responsible for maintaining the balance of fluids in both the intracellular and extracellular environments and determine the electrophysiological properties of myocardial membrane. ${ }^{8,9}$

Various factors, such as nutrition, absorption capacity of gastrointestinal tract, acid-base disorders, drug use, comorbid infections, or acute and chronic illness, individually or combined, play an important role in electrolytedisorder development. Electrolyte disorder is common in obese patients, and electrolyte derangement may contribute to the progress of disease and complications. ${ }^{7,10}$

Calcium $\left(\mathrm{Ca}^{2+}\right)$ ions play a pivotal role in cardiac muscle fibers during the excitation-contraction sequence, and are crucial in both central and peripheral vasculature. Over $99 \%$ of total body calcium is found in bones and teeth, and in conjunction with phosphorus to forms calcium phosphate in bones and teeth. ${ }^{11}$ Many biological processes, such as normal functioning of nerves and muscles, blood coagulation, and several enzymatic processes, are dependent on calcium. It is a versatile intracellular ion that is used throughout the life cycle of an organism to control various biological cascades and processes like insulin secretion. T2DM and cardiovascular diseases are associated with defects in calcium metabolism. $^{12}$ In a clinical setting, either increment (hypercalcemia) or decrement (hypocalcemia) of serumcalcium levels can depend on several pathologies and could be linked with severe life-threatening complications. Individuals with DM have higher total serum-calcium levels than their counterparts. ${ }^{13,14}$ Also, another crosssectional study showed that hypercalcemia was associated with high fasting plasma glucose, insulin resistance, and sensitivity in T2DM patients, but not with insulin secretion. ${ }^{13}$

Hypocalcemia impairs myocardial contractility, and there have been several studies explaining the derangement of calcium in obese patients, which in turn causes the development of elevated blood pressure. ${ }^{12}$ Hypocalcemia is a leading complication of diabetic nephropathy in patients with nephrotic syndrome, which leads to urinary loss of 25-hydroxyvitamin $\mathrm{D}_{3}$ and its carrier protein. On the contrary, elevated intracellular calcium concentration through a decrease in normal insulin-stimulated glucose transport increases the requirement for insulin, causing insulin overproduction and secretion resulting in hyperparathyroidism-mediated insulin resistance. Serum-calcium concentration should be evaluated in obese patients, because hyperparathyroidism has been related to complications in obese individuals. ${ }^{15,16}$

Chloride is the major extracellular anion that maintains a normal balance of body fluids. It plays a role in acidbase homeostasis, contributes to the maintenance of urine and plasma electroneutrality, and may also affect neuronal activation. $^{17,18}$

Mechanisms that lower sodium may also lower chloride levels, and low chloride levels may represent broader homeostatic abnormality. High serum-chloride values are associated with dehydration and decreased renal blood flow, such as in congestive heart failure. Hypochloremia in critically ill patients could be due to active $\mathrm{Cl}^{-}$loss, eg, through loss from the gastrointestinal tract (such as with vomiting diarrhea), through inadequate renal chloride reabsorption or dilution caused by infusion of hypotonic fluids. ${ }^{19,20}$ 
Hypochloremia increases the risk of mortality in subjects with hypertension, in which $\mathrm{Na}^{+}-\mathrm{Cl}^{-}$level is linked with the increased risk of metabolic syndrome in obese patients. This suggests the diagnostic utility of $\mathrm{Na}^{+}-\mathrm{Cl}^{-}$ levels as a provisional new risk marker for metabolic syndrome. ${ }^{16}$ Moreover, hyperchloremia results in longer ICU and hospital stay and mortality. In general, it is related to poor outcomes in critically ill patients. ${ }^{18,21}$

Disorders of calcium and chloride ions are among the top parameters used to determine the burden and severity of systemic and chronic diseases, in addition to response to treatment and presence of concurrent diseases. Despite this, chloride and calcium have received less attention than other ions. Also, both are commonly used in followup for obese patients. ${ }^{12,22}$ Though knowledge of the patterns of calcium and chloride disorders and related predictors in obese patients is crucial, derangements have not been well assessed, and limited data with conflicting results are available on calcium and chloride profiles in obese adults. Therefore, this study aimed to evaluate the magnitude of calcium and chloride derangements and predictors among adult obese patients attending the outpatient department at Wolkite University Specialized Hospital in southern Ethiopia.

\section{Methods}

\section{Study Setting and Design}

This institution-based cross-sectional study was conducted from May to August 2020 among obese patients at the outpatient department of Wolkite University Specialized Hospital, which is $173 \mathrm{~km}$ southwest of Addis Ababa.

\section{Study Population}

All obese patients attending the outpatient departmentserved as the source population, and all those selectedduring the study period were taken as the study population.

\section{Inclusion Criteria}

All obese adults (age $\geq 18$ years) participants attending the outpatient departmentwith central obesity (WC $\geq 102 \mathrm{~cm}$ for men and $\geq 88 \mathrm{~cm}$ for women) were enrolled. Those who did not meet the inclusion criteria and those with cancer, chronic kidney disease, critically diseased, or pregnant were excluded.

\section{Sample Size and Sampling Technique}

The sample size was determined using a single population-proportion formula with assumptions of expected frequency (prevalence of hypochloremia among obese patients) of $25.9 \%,{ }^{22} 95 \% \mathrm{CI}, 5 \%$ margin of error, and $10 \%$ nonresponse rate, which yielded 295. Finally, a correction formula was used, since the population was $<10,000$ (984), and we got a final sample size of 250. All consecutively identified participants who fulfilled the inclusion criteria were recruited.

\section{Data-Collection Techniques and Procedures}

A pretested structured questionnaires was developed by reviewing relevant literature and making certain modifications. ${ }^{15,23}$ The WHO's stepwise approach for incommunicable disease surveillance was adopted and similar literature used. ${ }^{24}$

For anthropometric measurement, weight was measured twice - at baseline and at the end of fasting with a digital measurement tool to the nearest $100 \mathrm{~g}$. Height was computed with a calibrated wooden measuring board to the nearest $0.1 \mathrm{~cm}$. BMI was computed by dividing weight $(\mathrm{kg})$ by height $\left(\mathrm{m}^{2}\right){ }^{25} \mathrm{WC}$ was measured between the lower margins of the least palpable rib and the top of the hip at the midpoint or minimal waist using stretchresistant tape. WC cutoff points usedindicating central obesity were $\geq 102 \mathrm{~cm}$ for men and $\geq 88 \mathrm{~cm}$ for women. ${ }^{7}$

\section{Physical/Clinical Examination}

Blood pressure was measured digitally using a mercury sphygmomanometer at the right upper arm after the subject had been seated for 5 minutes. ${ }^{26}$

\section{Specimen Collection and Analysis}

After obtaininging verbal consent from the participant, $5 \mathrm{~mL}$ blood was taken from each patient and collected using a serum-separator tube by trained laboratory technicians following standard operating procedures to determine serum-chloride and -calcium concentrations. Collected samples were kept for 30 minutes and serum separated from whole-blood sample by centrifugation at $3,000 \mathrm{rpm}$ for 10 minutes in thermostable conditions. Then, serum were identified and stored at $-20^{\circ} \mathrm{C}$ until biochemical analysis. Measurement of serum calcium and chloride was done using ion-selective electrode analysis at Wolkite University Specialized Hospital's laboratory department with a HumaLyte Plus ${ }^{5}$ following standard operating procedures. 


\section{Assays of Calcium and Chloride lons}

Ion-selective electrodes were used to analyze serum calcium and chloride. The International Federation of Clinical Chemistry recommends cutoff points to categorize calciumand chloride-ion values above and below the reference range. Accordingly, the reference point for chloride-ion concentration in the blood is $98-107 \mathrm{mmol} / \mathrm{L}$. Obese patients with serum-chloride concentrations $<98 \mathrm{mmol} / \mathrm{L}$ and $>107 \mathrm{mmol} /$ $\mathrm{L}$ were categorized as hypochloremic and hyperchloremic, respectively. Similarly, those with serum-calcium levels $<1.12 \mathrm{mmol} / \mathrm{L}$ and $>1.14 \mathrm{mmol} / \mathrm{L}$ were categorized as hypocalcemic and hypercalcemic, respectively. ${ }^{27}$

An ABX Pentra 400 was used to analyze serum glucose.

\section{Data-Quality Management}

All data and specimen collectors were overseen by a supervisor. According to the guidelines, specimens were collected, stored, and transported and those of low quality rejected. Working and acceptable kits were used. Supervisors checked daily performance. Measuring instruments were calibrated basedon their respective reference materials.

Both reagents and controls were checked for expiry dates. The ABX Pentra and HumaLyte Plus ${ }^{5}$ were checked for precision using normal and pathological controls. Before any sample had been processed, dual quality controls were done and results taken after quality had been deemed acceptable. Collected results were checked for completeness by the principal investigator.

\section{Data Analysis}

Data were cleaned, coded, entered into EpiData 3.1, and analyzed using SPSS 23.0. Frequency tables and descriptive summaries were used to depict study variables. Both bivariate and multivariate logistic regression analyses were done to identify associations between calcium and chloride disorders and independent variables. Variables with $P<0.25$ on bivariate analysis were candidates for multivariate logistic regression. Predictors having significant association with calcium and chloride disorders in the final model were identified at $P<0.05$ with $95 \%$ CIs of AORs. The appropriateness of the analysis model was checked with the Hosmer-Lemeshow test.

\section{Variables}

Selected electrolyte disorders were dependent variables, and independent variables were sociodemographic factors (age, sex, education, employment, and residence), behavioral factors (physical inactivity, cigarette smoking, and alcohol use), medication (diuretics, antidiabetics, ACE inhibitors, andcalcium-channel blockers), and anthropometric factors(height, weight, BMI, and WC).

Chloride and calcium disorders were taken as chlorideion level $<97 \mathrm{mEq} / \mathrm{L}$ or $>107 \mathrm{mEq} / \mathrm{L}$ and calcium level $<1.12 \mathrm{MEq} / \mathrm{L}$ or $>1.14 \mathrm{MEq} / \mathrm{L}$, respectively. ${ }^{28}$

Obesity was defined in terms of central obesity, in turn defined as $\mathrm{WC} \geq 102 \mathrm{~cm}$ for men and $\geq 88 \mathrm{~cm}$ for women). ${ }^{7}$

Physical inactivity was regarded as no moderate daily physical exercise or activities, such as walking or cycling that have important health benefits or not doing the recommended 30-60 minutes' aerobic exercise three to four times per week to promote cardiovascular fitness. ${ }^{29}$ Those defined as smokers had smoked one or more manufactured or handrolled cigarettes during data collection. Alcohol users were participants who drank more than three to four units for males and more than two to three units for females daily. ${ }^{30}$

Khat chewing was taken as any use of khat, irrespective of type, during the study. ${ }^{31}$

\section{Results}

A total of 250 sampled obese patients (response rate $100 \%$ ) were enrolled. Patient ages ranged 20-75 years, with mean age $50.5 \pm 12.9$ years. A majority (56\%) were aged $\geq 50$ years. Ninety (36\%) respondents had had no formal education, $206(83.2 \%)$ were married, and 96 $(38.4 \%)$ were farmers.

Mean height was $1.64 \pm 0.068(1.45-1.83)$ m,and weight $71.4 \pm 9.29$ (45-115) kg. Mean WC was 98.68 \pm 8.30 $(88-130) \mathrm{cm}$. Of the 250 patients, $219(87.6 \%)$ were diabetic and $151(60.4 \%)$ hypertensive. Insulin and other antidiabetics $(64 \%)$, diuretics $(42.8 \%)$, calcium-channel blockers (34.1\%), and ACE inhibitors (31.6\%) were medications commonly used. Regular fruit consumers were 114 (45.6) and a third were khat chewers, followed by alcohol users (20.8\%, Table 1$)$.

\section{Magnitude of Calcium- and Chloride-lon Disturbances}

The commonest electrolyte disorder was hypochloremia (18\%). The average serum-chloride level was 100.35 (95\% CI 53.02-111) mmol/L. The second-commonest disorder was hypercalcemia (17.6\%), and the average serum level of calcium among study subjects was 1.50 $\pm 1.49 \mathrm{mmol} / \mathrm{L}$, Table 2). 
Table I Sociodemographic and Other Characteristics of Participants $(n=250)$

\begin{tabular}{|c|c|c|c|}
\hline & Categories & $\mathbf{n}$ & $\%$ \\
\hline \multirow[t]{3}{*}{ Age, years } & $\geq 50$ & 140 & 56 \\
\hline & $25-49$ & 92 & 36.8 \\
\hline & $<25$ & 18 & 7.2 \\
\hline \multirow[t]{2}{*}{ Sex } & Female & 120 & 48 \\
\hline & Male & 130 & 52 \\
\hline \multirow[t]{2}{*}{ Residence } & Urban & 120 & 48 \\
\hline & Rural & 130 & 52 \\
\hline \multirow[t]{4}{*}{ Occupation } & Farmer & 96 & 38.4 \\
\hline & Daily laborer & 29 & 11.6 \\
\hline & Merchant & 94 & 37.6 \\
\hline & Civil servant & 31 & 12.4 \\
\hline \multirow[t]{4}{*}{ Education } & None & 90 & 36 \\
\hline & Primary & 57 & 22.8 \\
\hline & Secondary & 45 & 18 \\
\hline & Higher & 58 & 23.2 \\
\hline \multirow[t]{4}{*}{ Marital status } & Married & 208 & 83.2 \\
\hline & Single & 13 & 5.2 \\
\hline & Widowed & 21 & 8.4 \\
\hline & Divorced & 8 & 3.2 \\
\hline \multirow[t]{2}{*}{ FBS (mg/dL) } & $<110$ & 23 & 9.2 \\
\hline & $\geq 110$ & 227 & 90.8 \\
\hline \multirow[t]{2}{*}{ Systolic blood pressure } & $<130$ & 55 & 22 \\
\hline & $\geq 130$ & 195 & 78 \\
\hline \multirow{2}{*}{ Diastolic blood pressure } & $<85$ & 88 & 35.2 \\
\hline & $\geq 85$ & 162 & 64.8 \\
\hline \multirow[t]{2}{*}{ Alcohol consumption } & Yes & 52 & 20.8 \\
\hline & No & 198 & 79.2 \\
\hline \multirow[t]{2}{*}{ Khat chewer } & Yes & 76 & 30.4 \\
\hline & No & 174 & 69.6 \\
\hline \multirow[t]{2}{*}{ Sufficient fruit consumption } & Yes & 114 & 45.6 \\
\hline & No & 136 & 54.4 \\
\hline \multirow[t]{2}{*}{ Cigarette smoker } & Yes & 34 & 13.6 \\
\hline & No & 216 & 86.4 \\
\hline \multirow[t]{4}{*}{ Body-mass index $\left(\mathrm{kg} / \mathrm{m}^{2}\right)$} & $\geq 30$ & 63 & 25.2 \\
\hline & $25-29.9$ & 79 & 31.6 \\
\hline & $18.5-24.9$ & 71 & 28.4 \\
\hline & $<18.5$ & 37 & 14.8 \\
\hline
\end{tabular}

\section{Correlations Between Selected Serum-Electrolyte Parameters and Predictor Variables}

Calcium and chloride levels showed positive correlations with fasting blood sugar. Systolic blood pressure had a strong negative correlation with serum-calcium level $(r=0.56, P=0.037)$
Table 2 Selected-electrolyte Status of Participants $(n=250)$

\begin{tabular}{|l|l|l|l|}
\hline & Category & $\mathbf{n}$ & $\%$ \\
\hline Chlorine & Hypochloremia & 45 & 18 \\
& Normal & 199 & 79.6 \\
& Hyperchloremia & 6 & 2.4 \\
\hline \multirow{2}{*}{ Calcium } & Hypocalcemia & 24 & 9.6 \\
& Normal & 182 & 72.8 \\
& Hypercalcemia & 44 & 17.6 \\
\hline
\end{tabular}

and a strong positive correlation with serum-chloride level $(r=0.61, P=0.025)$. Diastolic blood pressure shown weak positive and negative correlations with serum-calcium and chloride levels $(r=0.21, P=0.035$ and $r=0.33, P=0.002$, respectively). Serum-calcium level showed a significant positive correlation with BMI $(r=0.211, P=0.014)$, and serumchloride level showed a very strong correlation with BMI (Table 3).

\section{Factors Associated with Hypochloremia and Hypercalcemia}

Bivariate and multivariate analyses were done for each predominant electrolyte disturbance on sociodemographic, behavioral, and biochemical factors. Patient age, diuretic use, physical inactivity, residence, and education were identified on bivariate analysis for multivariate analysis. Patient age, diuretic use, and BMI were significantly associated with hypochloremia. Physical inactivity and BMI were significantly associated with hypercalcemia. Patients on diuretics were more likely (AOR 2.35, 95\% CI 1.31-4.23) to develop hypochloremia than those not on diuretics.Physical inactivity increased the odds of hypercalcemia(AOR 4.28, 95\% CI 1.71-10.44). Furthermore, BMI was found to increase the odds of hypercalcemia more than ninefold (AOR 9.21, 95\% CI 2.50-14.8; Tables 4 and 5).

Table 3 Correlations Between Selected Serum Electrolytes and Predictors

\begin{tabular}{|l|l|l|l|l|}
\hline \multirow{2}{*}{} & \multicolumn{2}{l|}{$\mathrm{Ca}^{2+}$} & \multicolumn{2}{l|}{$\mathrm{Cl}^{-}$} \\
\cline { 2 - 5 } & $\boldsymbol{r}$ & $\boldsymbol{P}$ & $\boldsymbol{r}$ & $\boldsymbol{P}$ \\
\hline SBP & -0.056 & 0.037 & $0.6 \mathrm{I}$ & 0.025 \\
DBP & 0.021 & 0.035 & -0.33 & 0.002 \\
FBG & 0.023 & $0.04 \mathrm{I}$ & 0.150 & 0.018 \\
BMI & $0.21 \mathrm{I}$ & 0.014 & $0.7 \mathrm{I}$ & 0.026 \\
Hip circumference & -0.83 & 0.189 & $-0.07 \mathrm{I}$ & 0.215 \\
\hline
\end{tabular}

Abbreviations: SBP, systolic blood pressure; DBP, diastolic blood pressure; FBS, fasting blood sugar. 
Table 4 Bivariate and Multivariate Analysis of Factors Associated with Hypochloremia

\begin{tabular}{|c|c|c|c|c|c|}
\hline & \multirow[t]{2}{*}{ Categories } & \multicolumn{2}{|c|}{ Hypochloremia } & \multirow[t]{2}{*}{ COR $(95 \% \mathrm{Cl})$} & \multirow[t]{2}{*}{ AOR (95\% Cl) } \\
\hline & & Yes & No & & \\
\hline \multirow[t]{3}{*}{ Age, years } & $\geq 50$ & 66 & 74 & $4.46(2.26-15.62)^{*}$ & $3.58(2.58-11.10)^{* *}$ \\
\hline & $25-49$ & 36 & 56 & $3.21(1.77-12.67)^{*}$ & $2.97(0.67-13.18)$ \\
\hline & $<25$ & 3 & 15 & 1 & I \\
\hline \multirow[t]{2}{*}{ Residence } & Urban & 61 & 59 & $1.95(1.84-2.84)^{*}$ & $1.08(0.54-2.15)$ \\
\hline & Rural & 45 & 85 & 1 & 1 \\
\hline \multirow[t]{4}{*}{ Education } & None & 49 & 41 & $1.92(1.79-4.68)^{*}$ & $4.40(0.91-9.61)$ \\
\hline & Primary & 25 & 32 & $\mathrm{I} .69(0.64-4.5 \mathrm{I})$ & $1.91(0.85-4.33)$ \\
\hline & Secondary & 17 & 28 & $2.29(0.85-6.19)$ & $1.74(0.72-4.20)$ \\
\hline & Higher & 17 & 41 & 1 & 1 \\
\hline \multirow[t]{2}{*}{ Alcohol consumption } & Yes & 28 & 24 & $1.75(0.83-3.32)^{*}$ & $1.18(0.57-2.31)$ \\
\hline & No & 79 & 119 & 1 & 1 \\
\hline \multirow[t]{2}{*}{ Physically inactive } & Yes & 27 & 23 & $1.76(0.62-2.11)^{*}$ & $2.11(0.67-3.42)$ \\
\hline & No & 80 & 120 & 1 & \\
\hline \multirow[t]{2}{*}{ Diuretic use } & Yes & 61 & 46 & $2.79(1.63-4.54)^{*}$ & $2.35(1.3 \mathrm{I}-4.23)^{* *}$ \\
\hline & No & 46 & 97 & 1 & 1 \\
\hline \multirow[t]{4}{*}{ BMI } & $\geq 30$ & 38 & 25 & $6.51(2.3|-| 4.62)^{*}$ & $6.82(2.26-14.62)^{* *}$ \\
\hline & $25-29.9$ & 33 & 46 & $3.07(1.15-6.85)$ & $4.74(1.78-12.67)$ \\
\hline & $18.5-24.9$ & 29 & 42 & $2.95(1.08-6.65)$ & $3.33(1.24-8.90)$ \\
\hline & $<18.5$ & 7 & 30 & 1 & 1 \\
\hline
\end{tabular}

Notes: $* P<0.25 ; * * P<0.05 ; \mathrm{I}=$ reference.

Table 5 Bivariate and multivariate analysis of factors associated with hypercalcemia

\begin{tabular}{|c|c|c|c|c|c|}
\hline & \multirow[t]{2}{*}{ Categories } & \multicolumn{2}{|c|}{ Hypercalcemia } & \multirow[t]{2}{*}{ COR $(95 \% \mathrm{Cl})$} & \multirow[t]{2}{*}{ AOR $(95 \% \mathrm{Cl})$} \\
\hline & & Yes & No & & \\
\hline Sex & $\begin{array}{l}\text { Female } \\
\text { Male }\end{array}$ & $\begin{array}{l}31 \\
19\end{array}$ & $\begin{array}{l}89 \\
111\end{array}$ & $2.03(1.11-3.85)^{*}$ & $\begin{array}{l}1.96(0.65-3.82) \\
\text { I }\end{array}$ \\
\hline Residence & $\begin{array}{l}\text { Urban } \\
\text { Rural }\end{array}$ & $\begin{array}{l}29 \\
21\end{array}$ & $\begin{array}{l}91 \\
109\end{array}$ & I.65 $(0.84-2.84)^{*}$ & $\begin{array}{l}1.08(0.54-2.15) \\
\text { I }\end{array}$ \\
\hline Education & $\begin{array}{l}\text { None } \\
\text { Primary } \\
\text { Secondary } \\
\text { Higher }\end{array}$ & $\begin{array}{l}20 \\
12 \\
12 \\
7\end{array}$ & $\begin{array}{l}70 \\
45 \\
33 \\
51\end{array}$ & $\begin{array}{l}2.08(0.79-4.68)^{*} \\
1.94(0.64-4.5 \mathrm{I}) \\
2.64(0.85-6.19) \\
\mathrm{I}\end{array}$ & $\begin{array}{l}\text { I.77 }(0.69-4.55) \\
\text { I.69 (0.60-4.72) } \\
2.89(0.8 \mathrm{I}-8.40) \\
\mathrm{I}\end{array}$ \\
\hline Physically inactive & $\begin{array}{l}\text { Yes } \\
\text { No }\end{array}$ & $\begin{array}{l}35 \\
75\end{array}$ & $\begin{array}{l}15 \\
125\end{array}$ & $3.88(1.91-6.83)^{*}$ & $4.28(|.7|-\mid 0.44)^{* *}$ \\
\hline BMI & $\begin{array}{l}\geq 30 \\
25-29.9 \\
18.5-24.9 \\
<18.5\end{array}$ & $\begin{array}{l}10 \\
19 \\
15 \\
6\end{array}$ & $\begin{array}{l}53 \\
60 \\
56 \\
31\end{array}$ & $\begin{array}{l}0.97(0.33-2.64)^{*} \\
\mathrm{I} .63(0.57-3.92) \\
\mathrm{I} .38(0.45-3.32) \\
\mathrm{I}\end{array}$ & $\begin{array}{l}9.21(2.50-14.81)^{* *} \\
8.32(1.6 \mathrm{I}-10.20) \\
3.43(1.35-7.10) \\
1\end{array}$ \\
\hline
\end{tabular}

Notes: $* P<0.25 ; * * P<0.05 ; \mathrm{I}=$ reference.

\section{Discussion}

Electrolyte disorders are more common in obese patients, which could be a result of maldistribution of electrolytes due to hyperglycemia, shifting osmotic fluids, total-body deficits, loss due to sweating, diarrhea, or vomiting, and loss due to diuretics and hypothyroidism, which makes 
electrolytes in the body either high or low. ${ }^{32,33}$ Between the electrolyte disorders assessed, hypochloremia or low serum-chloride concentration was the more prevalent.

Results showed that hypochloremia affected $18 \%$ of the study subjects. This is lower than studies conducted in multispecialty hospitals in southern India, where $31 \%$ of participants were found to be hypochloremic, and at a university medical center in the Netherlands, where $25.9 \%$ of patients developed hypochloremia. A similar study was done in an Ethiopian hospital assessing of renal function and electrolyte balance in patients with cardiovascular disease, and $45 \%$ of patients had hypochloremia. ${ }^{22,34,35}$ The variation might be due to the inclusion of patients with with renal problems or a focus on those known to have a loss of renal concentrating capacity (electrolyte disorders in patients admitted with DM and complicated cardiac disease, respectively). However, our result was higher than the study done in Ethiopia, where $14.9 \%$ of patients were hypochloremic, and Okayama University Hospital, where $8.8 \%$ of patients had hypochloremia. The variation might be attributed to the majority of participants in this being diabetics with complications. Patients who have insulin resistance and fail to control their blood sugar are at a greater risk of hypochloremia, due to the inability of nephrons to maintain control of homeostatic mechanisms involving initiation of thirst, and renal handling and done in the critical care setting, where in acid-base and electrolyte abnormalities are common. Also, previous studies have used narrow reference ranges $(98-106 \mathrm{mEq} / \mathrm{L})$ and variability of study subjects may affect results. This study revealed that study participants aged $\geq 50$ years were at greater risk of hypochloremia (AOR 3.58, 95\% CI 2.58-11.10). This is in line with the Okayama University Hospital study. ${ }^{36}$ This might be due to advanced age impairing ability to control water and electrolyte homeostasis in response to environmental and dietary changes and dehydration due to decrement in body-water content, decreased fluid intake, injudicious use of diuretics, and predisposition to concomitant infections, or a combination of these. This result is also supported by studies in Asia that showed that chloride was decreased in admitted obese dyslipidemic patients of advanced age. ${ }^{19,23}$

DSiuretic use was significantly associated with hypochloremia: the odds of developing hypochloremia were 2.35-fold higher in participants on diuretics than nonusers. This is in line with studies conducted in Italy, China, and Ethiopia. ${ }^{28,37,38}$ This might be due to the fact that drugs, especially loop diuretics, are a major cause of hypochloremia in obese and hypertensive patients. Increased sodium delivery to distal tubular segments by loop diuretic-dependent inhibition of $\mathrm{Na}^{+}-\mathrm{K}^{+}-2 \mathrm{Cl}^{-}$in the thick ascending limb of the Henle loop enhances the expression and activity of the thiazide-sensitive cotransporters along the distal tubules. Moreover, reduction in chloride levels is attributed in increased $\mathrm{Na}^{+}-\mathrm{K}^{+}$ATPase activity on the basolateral membrane. ${ }^{23,38}$ Chloride ion is readily changed to regulate plasma strong ion difference and control the acid-base balance. Sodium and chloride are the major cation and anion in extracellular fluid and key factors in pronounced ion differences. The electrochemical effects of such differences affects water dissociation and hence hydrogenion concentration. As pronounced ion differences become more positive, the hydrogen ion, a "weak" cation, decreases to maintain electrical neutrality. ${ }^{18}$

The current study also showed that BMI was positively associated with hypochloremia (AOR 9.214, 95\% CI 2.5014.81), supported by similar study conducted in Ethiopia and South Korea. ${ }^{20,28}$ A possible explanation could be that excessive accumulation of fat leads to increased circulating blood volume, which increases cardiac output caused by stroke volume in obese patients and can be due to hemodilution from increased blood volume in high BMI or obesity. Another study stated that higher BMI can be a determining factor in increasing blood pressure and at the same time responsible for decremeased serum chloride and other electrolytes, which correlates with the findings of our study. ${ }^{20,39}$

The second-most disordered ions were for hypercalcemia $-17.6 \%$ of study subjects. This is lower than a study conducted in Cotonou, Benin, in which $23.3 \%$ of patients were hypercalcemic. ${ }^{15}$ This difference might be explained by sociodemographic variations between study subjects, behavioral factors, and living standards. On the contrary, the prevalence in this study was higher than studies in India and Ethiopia, where hypercalcemia was present in $3 \%$ and $10.9 \%$, respectively, ${ }^{28,40}$ of admitted metabolic syndrome patients. This disparity might be due to sociodemographic variations and differences in the spectrum of cases. Calcium is crucial for insulin-mediated intracellular processes in insulin-responsive tissue like skeletal muscles and adipose tissue, with a very narrow range needed for optimal function. Impairment of insulin-receptor phosphorylation leads to impaired insulin signal transduction and lowers glucose-transporter activity. Altered $\mathrm{Ca}^{2+}$ regulation in adipocyte metabolism may enhance triglyceride 
accumulation through increased de novo lipogenesis and failure to suppress insulin-mediated lipolysis, which leads to fat accumulation, impaired cellular calcium homeostasis, and defective skeletal muscles and liver and adipose tissue in patients with T2DM. ${ }^{16}$

Physically inactive patients were 4.28 times more likely to have hypercalcemia than their counterparts. A possible reason could be that physical exerciseinduces bone-mass gain, which will invariably modulate serum/plasma calcium-ion concentration. Parathyroid hormone, which regulates bone metabolism, functions to maintain calcium-ion concentration in extracellular fluids within its physiological limits. Both exercise duration and strength readily influence the role of parathyroid hormone. Those with a sedentary lifestyle are at significantly higher risk of developing hypercalcemia than more physically active people. ${ }^{41,42}$ Serum/plasma calcium and parathyroid-hormone concentration move in the opposite direction to exercise. Regular participation in more physical activities induces parathyroid "hypoactivity", which may be one potential explanation for future risk of developing primary hyperparathyroidism. ${ }^{41}$

This study also showed that higher BMI had a significant association with hypercalcemia (AOR 9.21, 95\% CI 2.50-14.81), supported by similar studies conducted in the US and Spain., ${ }^{6,43}$ A possible explanation could be that insulin resistance and secretion depend on calcium homeostasis in obese patients. Cross-sectional studies have associated increased serum-calcium concentration with markers of impaired glucose metabolism and enhanced risk of T2DM with cardiovascular complications in individuals with increased serum-calcium concentrations.o Calcium homeostasis depends highly on insulin resistance and secretion. Secretion of insulin in response to an increased level of plasma glucose is a $\mathrm{Ca}^{2+}$ dependent cascade. A change in insulin secretion is also involved with disorders in blood-glucose homeostasis, ${ }^{6}$ and enhanced cytosolic calcium is related to increased expression of GLUT4 transporters in muscle cells, which in turn enhances insulin-stimulated glucose-transport activity in these myocytes. ${ }^{11}$ Also, hyperparathyroidism is associated with long-term insulin resistance and relative insulin insufficiency, which leads to outcomes of obesity or deterioration of glycemic control. Because obesity increases the risk of cardiovascular disease, it has been hypothesized that calcium levels are associated with obesity and its components. It is thought that elevated intracellular free-calcium concentration (by decreasing stable insulin-stimulated glucose transport) results in an increased requirement for insulin, resulting in hyperparathyroidism, related insulin resistance, which leads to development of overt DM. ${ }^{12,44}$

\section{Limitations}

There might have been recall bias, since study subjects were asked about past situations. Also, causality cannot be inferred, due to the cross-sectional nature of the study.

\section{Conclusion}

Calcium- and chloride-ion disorders are common in obese patients and may be related to increased negative complications. These disorders are particularly common in obese patients with overt complications, older patients, and those on certain medications, in particular diuretics. Obese patients may receive complex drug regimens, some of which may be related to the disorders explained herein. Prevention of obesity, particularly through moderate physical exercise, a healthy diet, discontinuation of diuretics when possible, strict follow-up, and control of glucose levels is of paramount importance to avert ion disorders in obese patients. The most effective management of these derangements can be achieved by averting the underlying pathophysiological events.

\section{Data Sharing Statement}

The original data for the current study are available from the corresponding author upon reasonable request.

\section{Ethics}

Ethics clearance was obtained from the Wolkite University institutional review board. Administrative offices concerned were communicated with by formal written letters. Written informed consent was obtained from all study subjects after explaining the purpose and procedures of the study before enrollment, and those willing to participate were included. Confidentiality of information and privacy of subjects were assured by keeping their responses anonymous. Based on laboratory results, study subjects with severe form of electrolyte disorder were referred to physicians for further care. This study was conducted in accordance with the Declaration of Helsinki.

\section{Acknowledgments}

We would like to acknowledge Wolkite University College of Health Science, Department of Biomedical Science for allowing the study. Our appreciation also goes to the managers and staff members at Wolkite University Specialized 
Hospital for their assistance and cooperation. Finally, we would like to thank participants for their willingness to give relevant information.

\section{Author Contributions}

All authors made significant contributions to the work reported, whether in conception, study design, execution, acquisition of data, or analysis and interpretation of data, or all these areas, took part in drafting, revising, or critically reviewing the article, gave final approval to the version to be published, agreed on the journal to which the article has been submitted, and agree to be accountable for all aspects of the work.

\section{Funding}

The authors received no specific funding for this work.

\section{Disclosure}

The authors declare that they have no conflicts of interest for this work.

\section{References}

1. Roger MS, Mary ABF, Paul K, et al. Blood pressure, electrolytes, and body size: their relationships in young relatives of men with essential hypertension. Hypertension. 1980;2(4).

2. Tesfay GG, Mulugeta WA, Afework M. Overweight/obesity among adults in Northwestern Ethiopia: a community-based cross sectional study. Arch Public Health. 2020;76(18).

3. Consultation. Obesity: Preventing and Managing the Global Epidemic. 2000.

4. Teferi M, Worku A, Yeshaneh S. Overweight/obesity among adults in Northwestern Ethiopia. Arch Public Health. 2018;18(76).

5. Alba G, Mònica B, Antoni R, et al. Plasma vitamin D and parathormone are associated with obesity and atherogenic dyslipidemia Cardiovasc Diabetol. 2012;11(149):11.

6. Hien T, Jacob S, Grange JS, et al. The impact of obesity on the presentation of primary hyperparathyroidism. J Clin Endocrinol Metab. 2014;99(7):2364.

7. Thaman RG, Arora GP. Metabolic syndrome: definition and pathophysiology. J Physiol Pharmacol Adv. 2013;3(3):48-56. doi:10.5455/jppa.20130317071355

8. Liamis G, Rodenburg EM, Hofman A, et al. Electrolyte disorders in community subjects: prevalence and risk factors. Am J Med 2013;126(3):256-263. doi:10.1016/j.amjmed.2012.06.037

9. Datchinamoorthi S, Vanaj R, Rajagopalan B. Evaluation of serum electrolytes in type II diabetes mellitus. Int J Pharm Sci Rev Res. 2016;40(1):251-253.

10. Goldberg A, Hammerman H, Petcherski S, et al. Prognostic importance of hyponatremia in acute ST-elevation myocardial infarction. Am J Med. 2004;117(4):242-248. doi:10.1016/j.amjmed.2004.03.022

11. Ibrahim. Calcium level in diabetes type two patients. Acta Sci Microbiol. 2020;3(6):17.

12. Catalanoa $\mathrm{A}$, Chilàa $\mathrm{D}$, Bellonea $\mathrm{F}$, et al. Incidence of hypocalcemia and hypercalcemia in hospitalized patients. J Clin Transl Endocrinol. 2018;13:13.
13. Safaa AE, Wigdan AR, Nazik IA, et al. Serum calcium levels in correlation with glycated hemoglobin in type 2 diabetic sudanese patients. Adv Diabetes Metab. 2016;4(4):64.

14. Paredes S, Matta-Coelho C, Monteiro AM, et al. Copper levels, calcium levels and metabolic syndrome. Rev Port Pneumol Diabetes. 2016;11(3):99-105.

15. Eugenie AA, Thierry CM, Casimir D, et al. Electrolyte disturbances in diabetic patients in Cotonou. Benin Int J Res Med Sci. 2016;12 (4):5435.

16. Cunha KA, Magalhães EI, Loureiro LM, Sant'Ana LF, Ribeiro AQ, Novaes JF. [Calcium intake, serum vitamin D and obesity in children: is there an association?]. Rev Paul Pediatr. 2014;33(2):229.

17. Shikata $\mathrm{C}$, Kita $\mathrm{K}$. The incidence and prognostic value of hypochloremia in critically ill patients. Sci World J. 2012;7:7.

18. Carmen AP, Dominik U, Stephan VH, et al. Serum chloride levels in critical illness. Intensive Care Med Exp. 2018;10(6):14.

19. Joseph J, Sunil B, Andrew LC, Joseph J, Sunil B, Andrew LC. Hypochloraemia in patients with heart failure: causes and consequences. Cardiol Ther. 2020;9:347.

20. Hyung J, Sungwon K, Jung TP, et al. Baseline chloride levels are associated with the incidence of contrast-associated acute kidney injury. Sci Rep. 2017;7:8.

21. Kimura T, Hashimoto Y, Tanaka M, et al. Sodium-chloride difference and metabolic syndrome: a population-based large-scale cohort study. Intern Med. 2016;55(21):3085-3090. doi:10.2169/internalmedicine.55.7000

22. Glenn T. Hyperchloremia. Intensive Care Med Exp. 2018;10(6):14.

23. AShwIn K, MelIna S, ShnI A, et al. Electrolyte disturbances among diabetic patients admitted in a multi-specialty hospital in southern India. J Clin Diagn Res. 2019;13(2):15.

24. Strong KL, Bonita R. Investing in surveillance: a fundamental tool of public health. J Prev Soc Med. 2004;49(4):269-275.

25. Pokrywka L, Čabrić M, Krakowiak H. Body mass index and waist: hip ratio are not enough to characterise female attractiveness. Perception. 2006;35(12):1693-1697. doi:10.1068/p5506

26. Cai X, Li X, Fan W, et al. Potassium and obesity/metabolic syndrome: a systematic review and meta-analysis of the epidemiological evidence. Nutrients. 2016;8(4):183. doi:10.3390/nu8040183

27. Unachukwu MN, Engwa GA, Nwalo FN, et al. Influence of type 2 diabetes on serum electrolytes and renal function indices in patients. $J$ Clin Diagn Res. 2018;12(6):1-12.

28. Shiferaw BW, Waqtola CG, Delebo LA. Assessment of selected serum electrolyte and associated risk factors in diabetic patients. Diabetes Metab Syndr Obes. 2019;12:2817.

29. Carl JC, Kenneth EP, Gregory MC. Physical activity, exercise, and physical fitness: definitions and distinctions for health-related research. Public Health Rep. 1985;100:1-6.

30. World Health Organization. Programme on Substance Abuse; Approaches to Treatment of Substance Abuse. 1995.

31. John MC, Fabrizio S, Adenekan O, et al. Overview of literature and information on "khat-related" mortality: a call for recognition of the issue and further research. Ann Ist Super Sanita. 2011;47(4):445-464.

32. Palmer BF, Clegg DJ, Ingelfinger JR. Electrolyte and acid-base disturbances in patients with diabetes mellitus. $N$ Engl $J$ Med. 2015;373(6):548-559. doi:10.1056/NEJMra1503102

33. Kughapriya P, Evangeline J. Evaluation of serum electrolytes in ischemic heart disease patients. Natl J Basic Med. 2016;6(4):1-14.

34. Getahun C, Yekoye A, Senbeta GA, et al. Assessment of renal function and electrolyte balance in patients with cardiovascular disease at Tikur Anbessa Specialized Hospital, Addis Ababa, Ethiopia scientific. J Med Res. 2019;10(3):78.

35. Jozine M, Kevin D, Jennifer SH, et al. Hypochloremia, diuretic resistance, and outcome in patients heart failure. Circ Heart Fail. 2016;9(9):9.

36. Makiko T, Hiroshi M, Fumiaki T, et al. The incidence and prognostic value of hypochloremia in critically ill patients. Sci World J. 2012;12:7. 
37. Cristina M, Davide V, Molfino $M$, et al. Diuretic resistance in cardio-nephrology: role of pharmacokinetics, hypochloremia, and kidney remodeling. Kidney Blood Press Res. 2019;9:13.

38. Yang YY, Guangping L, Tong L. Hypochloremia in acute decompensated heart failure. Anticoagulant Relat Nephrol. 2015;66 (23): 2685 .

39. Toshihiro K, Yoshitaka H, Muhei T, et al. Sodium-chloride difference and metabolic syndrome. Intern Med. 2016;10:3090.

40. Qazi N, Ruqaya A, Sajad H, et al. Electrolyte abnormalities in patients admitted in emergency department of tertiary care institute: a cross sectional study. Int J Med Sci Public Health. 2014;3(11):1368. doi:10.5455/ijmsph.2014.150820143
41. Ugwuja SE, Obeagu EI, Ochei KC, et al. Effect of physical exercises on serum electrolyte. IOSR J Dent Med Sci. 2014;13(9):121.

42. Anand V, Curhan GC, Paik JM, et al. Physical activity and the risk of primary hyperparathyroidism. J Clin Endocrinol Metab. 2016;101 (4):1597.

43. Nerea B-T, Ram E, M onica B, et al. Increased serum calcium levels and risk of type 2 diabetes in individuals at high cardiovascular risk. Diabetes Care. 2014;37:3091.

44. Changhwan A, Ji-Houn K, Eui-Bae J. Calcium homeostasis in diabetes mellitus. J Vet Sci. 2017;18(3):266.

\section{Publish your work in this journal}

Diabetes, Metabolic Syndrome and Obesity: Targets and Therapy is an international, peer-reviewed open-access journal committed to the rapid publication of the latest laboratory and clinical findings in the fields of diabetes, metabolic syndrome and obesity research. Original research, review, case reports, hypothesis formation, expert opinion and commentaries are all considered for publication. The manuscript management system is completely online and includes a very quick and fair peer-review system, which is all easy to use. Visit http://www.dovepress.com/testimonials.php to read real quotes from published authors. 